\title{
Lean Manufacturing Approach to Improve Speaker Manufacturing Process
}

\author{
Nastiti Puji Lestari ${ }^{1}$ and Putu Dana Karningsih ${ }^{2}$ \\ ${ }^{1}$ Department of Technology Management, Institut Teknologi Sepuluh Nopember, Surabaya, Indonesia \\ ${ }^{2}$ Department of Industrial Engineering, Institut Teknologi Sepuluh Nopember, Surabaya, Indonesia \\ e-mail: lestari.nastitipuji@gmail.com
}

\begin{abstract}
PT Y is a subsidiary of Y Group which specializes in producing speakers for local and international markets. At present PT Y's orders have not met the expected performance targets. Fulfillment of production orders reached $97.55 \%$ of the target of $100 \%$. This is one of the concerns of Y Group that PT $Y$ need to improve themselves because it can result in companies becoming less competitive than competitors. Based on preliminary observations, there was indications of waste, namely defects, downtime, and process delays. The lean tool used for further waste analysis is Lean Assessment Matrix (LAM). The results of the research show that the waste which gives the most significant influences are transportation, waiting and inventory. The root causes of problems between work stations are not ergonomic, do not have preventative maintenance schedules, there are no standards for handling defective products, the layout of the room is not in the direction of material, the carrying capacity of hand trucks is small, and the Outgoing Quantity Check (OQC) processes are not included in the company's time standards. The proposed improvement recommendations include conducting training to improve product repair skills, relayout of production plant, and making a preventative machine maintenance schedule.
\end{abstract}

Keywords-Lean Assessment Matrix, Lean Manufacturing, Process Activity Mapping, Value Stream Mapping, Waste Elimination.

\section{INTRODUCTION}

$\mathrm{P}$ T Y is a subsidiary of Group Y which specialize in producing speakers for local and international market. Speaker products fall into the category of audio equipment consisting of three groups, namely Audio-Visual Products (AV) for customers (customers), Professional Audio Equipment (PA) for the music industry and music activists, and Information and Communication Technology Devices (ICT) such as networks voice-based communication devices and equipment.

PT Y has a policy in determining reasonable overtime (forecast overtime) based on the availability of labor at a certain time based on the availability of labor and the level of demand for the company's products. In 2018, the actual overtime of PT Y is higher than the forecast overtime. Based on Figure 1, it is known that the actual overtime of PT Y generally fluctuates with the tendency of actual overtime to be higher than the forecast overtime.

The production process at PT Y is carried out in several parts of Wood Working (WW), Speaker Processing Unit (SPU), Painting, Printed Circuit Board (PCB), Rear Panel Assembly (RPA), and Sub-Assembly (SA) before being assembly as the final product in Final Assembly (FA). For the

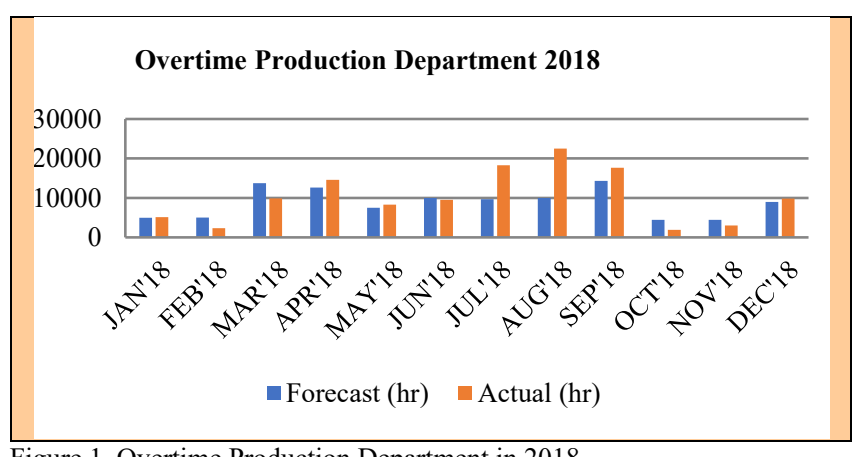

Figure 1. Overtime Production Department in 2018.

production process in the FA section to run smoothly, the input from the process in the previous section must run smoothly and without delay. The biggest cause of loss time in the FA process is the PCB section of 198.88 hours per year, followed by the PTG section 124.97 hours per year, and the WW section 120.93 hours per year.

The PCB process is the process of making electrical components used in speakers. Some of the processes carried out in the PCB section include the Surface Mount Technology (SMT) process, the Auto Insert (AI) process, and the Manual Insert (MI) process. In the SMT and AI process is carried out using a production machine, while in the MI process is carried out by the operator manually (by using a production tool). The initial process of the series of production processes in the $\mathrm{PCB}$ section is the SMT process. In the SMT process there are two production lines that support the entire production process at PT Y. In 2018, the average downtime on SMT line 1 is $19.11 \%$ and SMT line 2 is $21,00 \%$. This level of downtime does not meet the standards of the Japanese Institute of Plant Maintenance (JIPM) which states that the acceptable value of downtime is $\leq 10 \%$ [1].

In PCB MI process, the problems faced include defect which causes the production process to not run smoothly because it has to go through a rework and repair process. As a percentage, the number of defects in the PCB section is very low with a percentage of less than one percent of production output. However, the percentage of electric NG to overall NG is quite large with a range between $16.89 \%$ to $36.20 \%$. Electrical NG is the functional defect of components caused by process or material errors that cannot be identified only from the appearance of PCB. If there is an electrical NG, Production Engineering Department (PE-Repairmen) needs to do an analysis of the NG. The average analysis until it can be decided whether the PCB can be repaired (OK), Not Good (NG), Scrap (discarded), or EXPE (further PE-Repairmen analysis) is 3 days with an analysis deadline of two weeks. 


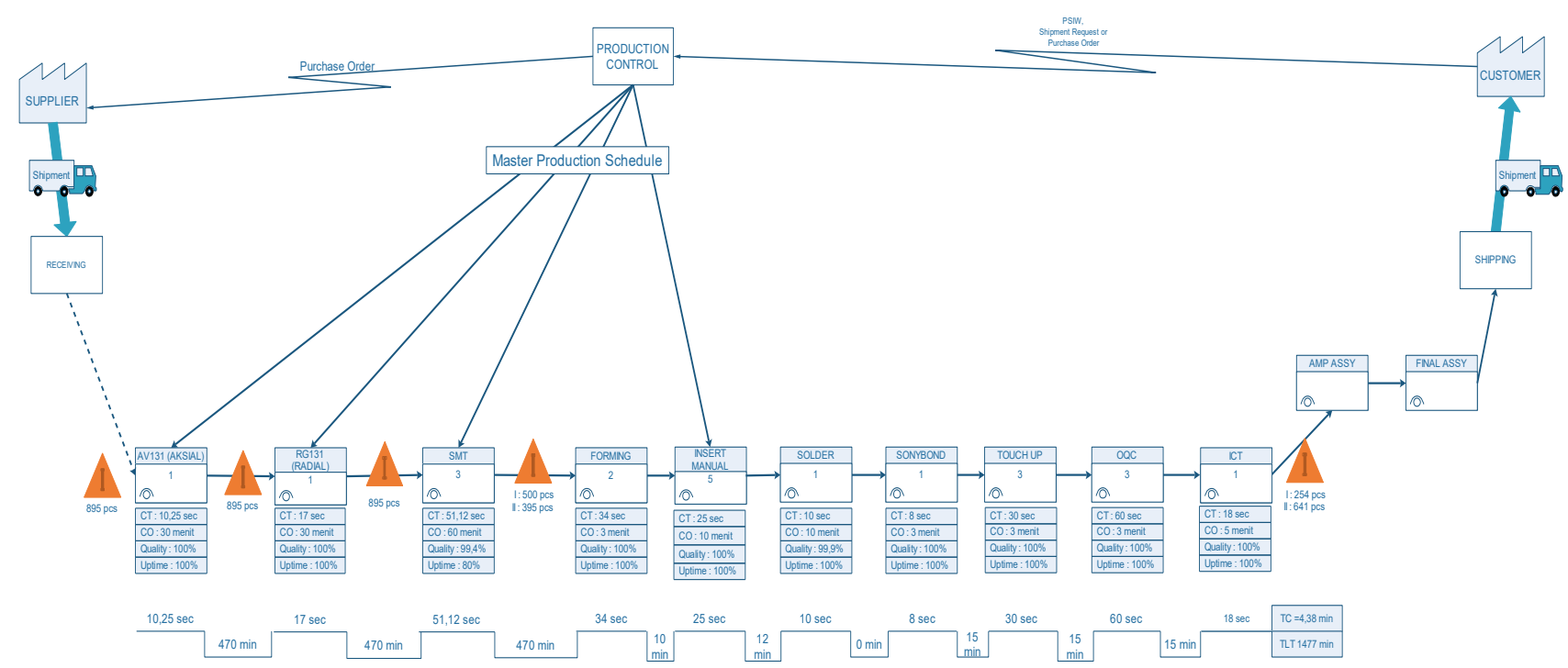

Figure 2. Value Stream Mapping of Speaker Production Process in PCB Section.

Table 3.

Activities in Speaker Production Process in PCB Section

\begin{tabular}{cccc}
\hline \hline $\mathrm{W}$ & Total & Time $(\mathrm{sec})$ & Percentage \\
\hline VA & 21 & 1592,58 & $20 \%$ \\
NVA & 34 & 78715,71 & $33 \%$ \\
NNVA & 48 & 29712,73 & $47 \%$ \\
Total & 103 & 110021,02 & $100 \%$ \\
\hline \hline
\end{tabular}

Table 4.

\begin{tabular}{|c|c|c|c|}
\hline Activity & Total & Time $(\mathrm{sec})$ & Percentage \\
\hline $\mathrm{O}$ & 60 & $23.621,92$ & $58 \%$ \\
\hline $\mathrm{T}$ & 15 & $25.667,67$ & $15 \%$ \\
\hline I & 21 & $7.342,43$ & $20 \%$ \\
\hline $\mathrm{S}$ & 3 & $10.800,00$ & $3 \%$ \\
\hline D & 4 & $42.589,00$ & $4 \%$ \\
\hline Total & 103 & 110021,02 & $100 \%$ \\
\hline
\end{tabular}

Table 5.

Waste Code

\begin{tabular}{ll}
\hline \hline Code & Description \\
\hline W1 & Defect Part Warping \\
W2 & Defect Electrical Error \\
W3 & WIP Inventory \\
W4 & Excessive movement on the component insert operator \\
W5 & High machine downtime \\
W6 & The process of repairing defect products \\
W7 & Circular material flow \\
W8 & Much time needed in WIP transfer time \\
W9 & Overinspection \\
W10 & Mark the PCB destination on the PWB \\
\hline \hline
\end{tabular}

This is very detrimental considering the company uses a weekly shipping policy (weekly shipping) in shipping finished products. These waste cause the total fulfillment of company orders in one year by $97.55 \%$, have not been able to meet the $100 \%$ target as set by the company.

Based on the explanation above, it can be seen that in the initial observation there was a waste problem that occurred at PT Y which resulted in the company not being able to meet the $100 \%$ order fulfillment target. Companies need improvements in the production process to be able to eliminate waste to support the company's mission of supporting increased productivity and elimination of waste.In this research lean was chosen because lean philosophy aims to reduce the waste that exists in the company by identifying and continually pursuing customer satisfaction. Lean
Table 1.

Root Causes of Waste Code

\begin{tabular}{ll}
\hline \hline Code & Description \\
\hline S1 & Partial inspection \\
S2 & No specific schedule for ICT machine maintenance \\
S3 & Production duration of each process is different \\
S4 & The workstation is not ergonomic \\
S5 & The company do not have a preventive maintenance schedule \\
S6 & There is no standard in handling defect product \\
S7 & Room layout that does not adjust the direction of the material \\
S8 & Capacity of hand truck for WIP transportation is small \\
S9 & OQC process is not standard \\
S10 & There is no PWB destination marking standard \\
\hline \hline
\end{tabular}

Table 2.

Waste Type Weight Calculation Results

\begin{tabular}{lllllllll}
\hline \hline $\mathrm{F} / \mathrm{T}$ & $\mathrm{O}$ & $\mathrm{I}$ & $\mathrm{D}$ & $\mathrm{M}$ & $\mathrm{T}$ & $\mathrm{P}$ & $\mathrm{W}$ & SCORE \\
\hline $\mathrm{O}$ & 0 & 0 & 0 & 0 & 0 & 0 & 0 & 0 \\
$\mathrm{I}$ & 0 & 0 & 4 & 7 & 6 & 8 & 5 & 30 \\
$\mathrm{D}$ & 0 & 8 & 0 & 5 & 5 & 5 & 5 & 28 \\
$\mathrm{M}$ & 0 & 8 & 4 & 0 & 8 & 6 & 5 & 31 \\
$\mathrm{~T}$ & 0 & 10 & 4 & 10 & 0 & 6 & 4 & 34 \\
$\mathrm{P}$ & 0 & 7 & 2 & 7 & 7 & 0 & 6 & 29 \\
$\mathrm{~W}$ & 0 & 5 & 4 & 8 & 10 & 5 & 0 & 32 \\
SCORE & 0 & 38 & 18 & 37 & 36 & 30 & 25 & 184 \\
$\%$ & 0 & 20,7 & 9,8 & 20,1 & 19,6 & 16,3 & 13,6 & 100 \\
& $\%$ & $\%$ & $\%$ & $\%$ & $\%$ & $\%$ & $\%$ & $\%$ \\
\hline \hline
\end{tabular}

philosophy is based on three basic rules including determining value, eliminating waste, and forming a smooth flow [2]. Lean manufacturing is a production philosophy that emphasizes the minimization of the use of resources (including time) used in activities carried out at the company, including identification and elimination of non-value-added activities in the process of design, production, supply chain management, and dealing with customers [3]

The product chosen in this study is the AA-series model because this product has the largest volume produced through the PCB process. Total AA-series production in one year reached 208.792 units with an average production per month of 17.399 units. The AA-series production process goes through several stages, namely WW, SPU, Injection, PCB, SA, RPA, and final assembly in the FA.

In this study the mapping of value added and non-value added activities with value stream mapping and process 
The $1^{\text {st }}$ International Conference on Business and Engineering Management (IConBEM)

February $1^{\text {st }} 2020$, Institut Teknologi Sepuluh Nopember, Surabaya, Indonesia

Table 6 .

Determination of Severity Level of Waste Result

\begin{tabular}{llc}
\hline \hline Code & Description & Severity Level of Waste \\
W1 & Defect Part Warping & 8 \\
W2 & Defect Electrical Error & 8 \\
W3 & WIP Inventory & 6 \\
W4 & Excessive movement on the component insert operator & 7 \\
W5 & High machine downtime & 10 \\
W6 & the process of repairing defect products & 8 \\
W7 & Circular material flow & 8 \\
W8 & Much time needed in WIP transfer time & 9 \\
W9 & Overinspection & 2 \\
W10 & Mark the PCB destination on the PWB & 1 \\
\hline \hline
\end{tabular}

Table 7.

Determination of Occurrence Level of Root Source of Waste Result (RSOWR)

\begin{tabular}{llc}
\hline \hline Code & Description & Occurrence level of RSOWR \\
\hline S1 & Partial inspection & 4 \\
S2 & No specific schedule for ICT machine maintenance & 9 \\
S3 & Production duration of each process is different & 10 \\
S4 & The work station is not ergonomic & 10 \\
S5 & The company do not have a preventive maintenance schedule & 8 \\
S6 & There is no standard in handling defect product & 8 \\
S7 & Room layout that does not adjust the direction of the material & 10 \\
S8 & Capacity of hand truck for WIP transportation is small & 10 \\
S9 & OQC process is not standard & 10 \\
S10 & There is no PWB destination marking standard & 10 \\
\hline \hline
\end{tabular}

Table 8 .

Lean Matrix 1

\begin{tabular}{|c|c|c|c|c|c|c|c|c|c|c|c|c|c|c|c|}
\hline \multicolumn{16}{|c|}{ Root Source of Waste } \\
\hline Waste Type & $\begin{array}{l}\text { Non } \\
\text { Added } \\
\text { Value } \\
\text { Activity } \\
\text { (Waste) }\end{array}$ & S1 & $\mathrm{S} 2$ & S3 & S4 & S5 & S6 & S7 & S8 & S9 & $\mathrm{S} 10$ & $\begin{array}{l}\text { Waste } \\
\text { Type } \\
\text { Weight }\end{array}$ & $\begin{array}{l}\text { Severity } \\
\text { level of } \\
\text { Waste }\end{array}$ & $\begin{array}{l}\text { Aggregate } \\
\text { Waste } \\
\text { Number }\end{array}$ & $\begin{array}{l}\text { Priority } \\
\text { Rank } \\
\text { of } \\
\text { Waste }\end{array}$ \\
\hline \multirow{2}{*}{ Defect } & W1 & 9 & & & & 3 & 3 & & & & & 15,2 & 8 & $10.214,40$ & 8 \\
\hline & W2 & & 9 & & 1 & 3 & 3 & & & & & 15,2 & 8 & $16.902,40$ & 6 \\
\hline Inventory & W3 & & 3 & 9 & & & & & 3 & 3 & & 16,3 & 6 & $17.310,60$ & 5 \\
\hline \multirow{2}{*}{ Waiting } & W5 & & & 3 & & 9 & & & & & & 17,4 & 10 & 17.748 & 4 \\
\hline & W6 & & & & 1 & 9 & 9 & 1 & & & & 17,4 & 8 & $22.828,80$ & 3 \\
\hline \multirow{2}{*}{ Transportation } & W7 & & & & 3 & & & 9 & 9 & & & 18,5 & 8 & 31.080 & 2 \\
\hline & W8 & & & 1 & 3 & & & 9 & 9 & & & 18,5 & 9 & 36.630 & 1 \\
\hline Unnecessary & W9 & & & & & & 3 & & & 9 & & 15,8 & 2 & $3.602,40$ & 9 \\
\hline Process & W10 & & & & & & & & & & 9 & 15,8 & 1 & 1.422 & 10 \\
\hline \multicolumn{2}{|c|}{$\begin{array}{l}\text { Occurrence level of Root } \\
\text { Source of Waste j } \\
\text { Aggregate Cause }\end{array}$} & 4 & 9 & 10 & 10 & 8 & 8 & 10 & 10 & 10 & 10 & & & & \\
\hline
\end{tabular}

activity mapping. The lean manufacturing approach used for waste elimination is carried out with the Lean Assessment Matrix (LAM) developed by [4]. This method is a modification and integration of the House of Risk (HOR) and Waste Relationship Matrix (WRM) that can comprehensively fulfill all stages of lean manufacturing implementation from waste and root causes of waste, determination of critical waste, alternative actions to eliminate root causes of waste and its priorities. With the combination of tools used in this study, it is expected to be able to solve the problems that occur at PT Y, especially at the PCB Production Department.

\section{RESEARCH METHODOLOGY}

\section{A. Identification of Waste and Its Causes}

Waste identification phase and its causes consist of observation and interviews, preparation of production process flowcharts, preparation of process activity mapping (PAM), compilation of current state value stream mapping, waste mapping, and root cause analysis of waste.

\section{B. Critical Waste Analysis}

The critical waste analysis consists of determining the type of waste weight obtained from the results of the waste relationship matrix, determining the severity level of waste, determining the occurrence level of the root source of waste, and the mapping of Lean Matrix 1.

\section{Recommendations for Improvement}

The design of improvement recommendations consists of several stages, namely the preparation of a number of alternative recommendations for improvement that form waste elimination actions (WEA). WEA will be the input of Lean Matrix 2. The preparation of Lean Matrix 2 requires several inputs, namely the calculation of the total effectiveness of WEA, determination of the degree of difficulty performing action determined by the company's experts, and calculation of the effectiveness to difficulty ratio. Lean matrix 2 will produce output in the form of rank of action priority that will be submitted to the company. 
The $1^{\text {st }}$ International Conference on Business and Engineering Management (IConBEM)

February $1^{\text {st }} 2020$, Institut Teknologi Sepuluh Nopember, Surabaya, Indonesia

Table 9

Alternative Recommendations for Improvement

\begin{tabular}{ll}
\hline \hline Code & Description \\
\hline WEA1 & Create ergonomic work station \\
WEA2 & Make preventive maintenance schedule \\
WEA3 & Make defect product handling standard \\
WEA4 & Relayout PCB MI room in the direction of material \\
WEA5 & Move the location of PCB MI between PCB SMT and FA \\
WEA6 & Conduct training to improve product repair skills \\
WEA7 & Increase material handling tools. \\
WEA8 & Integrate OQC in every production process \\
\hline \hline
\end{tabular}

\section{Conclusion and Suggestion}

At this stage the conclusion of the research is carried out which answers the research objectives by considering the results of the research analysis. After conclusions are drawn, suggestions are made to the company and to further research.

\section{RESEARCH RESULTS AND DISCUSSION}

Value Stream Mapping (VSM)Value Stream Mapping is created based on [5]. From VSM in Figure 2, it can be identified that there is inventory waste in several production processes, including AV131 process, RG131 process, the SMT process, and the ICT process before the product is sent to the AMP Assy process. Other wastes that can be identified from VSM are defects that occur in the SMT process by $0.6 \%$ and in the solder process by $0.1 \%$. The total cycle time of AAseries production is 9.3 minutes while the process lead time is 1.479 minutes. The changeover time in the value stream mapping indicates the different destinations (export destinations) of products that require production time to change product destinations related to the use of different material components

\section{A. Process Activity Mapping (PAM)}

Process Activity Mapping (PAM) is used to describe activities that occur in the PT Y PCB. PAM is made by describing the process, time, distance, manpower and type of activity (value added or not) [6]. The result of PAM can be seen in Table 1.

Based on Table 1, it is known that in the speaker production process the activity consist of necessary non value added activity (NNVA) of $47 \%$, non value added activity (NVA) of $33 \%$, and value added (VA) activity of $20 \%$. Based on Table 2 , the most activities are operation (58\%), inspection (20\%), transportation $(15 \%)$, delay $(4 \%)$, and storage $(3 \%)$. Transportation activities and delays are nonvalue added activities and must be reduced to increase productivity. Waste will then be analyzed in the Lean Assessment Matrix.

\section{B. Lean Assessment Matrix}

\section{1) Lean Matrix 1}

\section{a. Waste Mapping}

Based on observation and brainstorming with the company, identification of waste in PCB production process as follows: 1. Overproduction

There is no overproduction waste because the company production system is make to order.

\section{Defect}

There are seven types of defects that found in PCB production process namely part warping, electrical error, wrong polarity, poor solder, part missing, wrong part, solder bridge, part shifted, and part standing. The highest type of defect is part warping by $0.85 \%$, then the electrical error is $0.1 \%$, and wrong polarity by $0.02 \%$. Part warping is a defect that is closely related to the quality of materials from suppliers and handling of this material. For electrical error, further analysis must be done and requires a longer handling time.

\section{Inventory}

From VSM, it can be seen that some PCB processes produce inventory in the form of WIP finish AV, WIP finish $\mathrm{RG}$, and WIP finish MI. The average WIP storage time is 470 minutes or one production shift.

4. Motion

The results of observation and activity mapping on VSM and PAM show the existence of waste motion, which is excessive movement on the component insert operator. This is due to the position, the operator is on the right / left of a short conveyor containing material. This position causes the operator to turn around when retrieving and replacing the PCB from the conveyor. There are also operators who have difficulty reaching material components

5. Waiting

There are two kinds of waste waiting: high machine downtime and the process of repairing defect products.

\section{Transportation}

Circular material flow in the placement of PCB Assy on the production floor and WIP transfer time is longer because the production locations are on different floors (SMT and AI on the 1st floor; MI on the 2nd floor)

\section{Unnecessary Process}

This waste include over inspection and mark the PCB destination on the Printed Wire Board (PWB) Further discussion regarding waste will follow Table 3

b. Analysis of Root Causes of Waste

The root causes of waste are analyzed using 5 Why based on [7] and is shown in Table 4.

\section{c. Calculation of Waste Type Weight}

Waste type weight calculation is compiled from waste relationship matrix (WRM) questionnaire based on [8]. The questionnaire was answered by company experts. Waste type weight calculation results can be seen in Table 5. Based on Table 5, it can be seen that the highest percentage of waste is transportation (18.5\%), waiting (17.4\%), and motion (16.3\%). For waste overproduction, as described in Section 3.3.1.1, no waste overproduction is found, so the value of waste type weight is 0 .

d. Determination of Severity Level of Waste

Determination of severity level of waste is determined by the company's experts. The expected output from determining the severity level is a value on a scale of 1 to 10 and will then be used as a component in the preparation of lean matrix 1 . The result of determination of severity level of waste can be seen in Table 6.

e. Determination of Occurrence Level of Root Source of Waste

Determination of the occurrence level aims to determine the likelihood or frequency of waste occurring on the production floor. Determination of the occurrence level of the root cause of waste is determined by the company's expert. The expected output from determining occurrence levels is a 
The $1^{\text {st }}$ International Conference on Business and Engineering Management (IConBEM)

February $1^{\text {st }} 2020$, Institut Teknologi Sepuluh Nopember, Surabaya, Indonesia

Table 10.

Determination of Degree of Difficulty Performing Action

\begin{tabular}{|c|c|c|c|}
\hline Code & Description & Cost & Value \\
\hline WEA1 & Create ergonomic work station & Rp $\quad 19.200 .000,00$ & 4 \\
\hline WEA2 & Make preventive maintenance schedule & $\mathrm{Rp} \quad 2.880 .000,00$ & 3 \\
\hline WEA3 & Make defect product handling standard & $\mathrm{Rp}$ & 3 \\
\hline WEA4 & Relayout PCB MI room in the direction of material & $\mathrm{Rp} \quad 35.000 .000,00$ & 4 \\
\hline WEA5 & Move the location of PCB MI between PCB SMT and FA & Rp $550.000 .000,00$ & 5 \\
\hline WEA6 & Conduct training to improve product repair skills & $2.000 .000,00$ & 3 \\
\hline WEA7 & Increase material handling tools. & $750.000,00$ & 3 \\
\hline WEA8 & Integrate $\mathrm{OQC}$ in every production process & $\mathrm{Rp}$ & 3 \\
\hline
\end{tabular}

Table 11

Lean Matrix 2

\begin{tabular}{|c|c|c|c|c|c|c|c|c|c|c|}
\hline & & Waste $\mathrm{B}$ & imination & ction & & & & & & \\
\hline Waste Type & $\begin{array}{l}\text { Root Source of } \\
\text { Waste }\end{array}$ & WEA1 & WEA2 & WEA3 & WEA4 & WEA5 & WEA6 & WEA7 & WEA8 & $\begin{array}{l}\text { Aggregate } \\
\text { Cause }\end{array}$ \\
\hline & S3 & & & & 1 & & & 1 & & 930 \\
\hline & S4 & 9 & & & 3 & & & & & 1.300 \\
\hline & S5 & & 9 & & & & 3 & & & 1.680 \\
\hline I ransportation, Watting, & S6 & & & 9 & & & 9 & & & 1.176 \\
\hline Inventory & S7 & & & & 9 & 3 & & & & 1.680 \\
\hline & S8 & & & & & 9 & & 3 & & 1.710 \\
\hline & S9 & & & & & & & & 9 & 360 \\
\hline $\begin{array}{l}\text { Total Effectiveness of } \mathrm{W} \\
\text { Action } \mathrm{m}\left(\mathrm{TE}_{\mathrm{m}}\right)\end{array}$ & ste Elimination & 11.700 & 15.120 & 10.584 & 19.950 & 20.430 & 15.624 & 6.060 & 3.240 & \\
\hline $\begin{array}{l}\text { Degree of difficulty perfo } \\
\left(\mathrm{D}_{m}\right)\end{array}$ & ming action $\mathrm{m}$ & 4 & 3 & 3 & 4 & 5 & 3 & 3 & 3 & \\
\hline Effectiveness to difficulty $r$ & tio $\left(\mathrm{ETD}_{\mathrm{m}}\right)$ & 2.925 & 5.040 & 3.528 & $4.987,50$ & 4.086 & 5.208 & 2.020 & 1.080 & \\
\hline Rank of action priority & & 6 & 2 & 5 & 3 & 4 & 1 & 7 & 8 & \\
\hline
\end{tabular}

value on a scale of 1 to 10 and will then be used as a Training priority that needs to be done is mechanical/electrical component in the compilation of Lean Matrix 1. The result of determination of occurrence level of root source of waste can be seen in Table 7 .

f. Lean Matrix 1 Mapping Results

The mapping result of Lean Matrix 1 can be seen in Table 8. The calculation step is following [4]. The result of Lean Matrix 1 are priority rank of waste (transportation, waiting, and motion) that need to be analyzed more in Lean Matrix 2.

\section{2) Lean Matrix 2}

a. Alternative Recommendations for Improvement

Alternative recommendations for improvement are made after knowing the type of waste that must be prioritized to be eliminated. It is obtained from discussions with relevant parties from company. Alternative recommendations for improvement can be seen in Table 9.

b. Determination of Degree of Difficulty Performing Action

The results of determination of degree of difficulty performing action by experts from the company can be seen in Table 10. The determination is by looking at work (projects) of similar improvements that have been carried out in the past and projecting on current improvement recommendations.

\section{c. Lean Matrix 2 Mapping Results}

The mapping result of Lean Matrix 2 can be seen in Table 11. The calculation step is following [4]. The result of Lean Matrix 2 are rank of action priority of waste elimination. From Table 11, the actions that were chosen: WEA6, WEA4, and WEA2.

\section{3) Submission of Selected Recommendations based on Rank} Action of Priority

Selected recommendations based on rank action priority: a. WEA6: Conduct training to improve product repair skills repairs carried out on the SMT and MI operator. Training is conducted to improve the operator's skills in repairing products that have defects, so that if a defect occurs, the operator can troubleshoot directly and minimize the number of defects that must be analyzed by the repairmen. In addition, training will also focus on following skills:

1. Understanding schematic diagrams

2. Mastering and understanding all types of PCB parts

3. Can operate a rework station

4. Mastering the standard specification of inspection PCB

5. Can use solder pots

6. Can touch up repair products

This training will be conducted by PT Y internal employees so that it does not incur large costs. Costs incurred are the costs of providing modules, control cards, and progress reports on the training that will be conducted. The benefit prediction of this training subject to electrical error is $\mathrm{Rp}$ 145.124.392,00,0

b. WEA2: Make preventive maintenance schedule

Preventive maintenance schedules are made for the machines of all PCB sections. Four people (2 people from Production Engineering and 2 people from production) are responsible for carrying out preventive maintenance machines. The benefit prediction of this preventive maintenance schedule subject to corrective maintenance is $\mathrm{Rp}$ 26.437.700,00.

c. WEA4: Relayout PCB MI room in the direction of material

This change was made by adding goods entrances so that the WIP finish SMT was placed close to the insert material process. If WIP finish SMT has been placed near the material insert process, the direction of material flow is in the same direction and does not require high transportation. The benefit prediction of relayout PCB MI room subject to transportation is $\operatorname{Rp} 9.676 .000,00$. 
The $1^{\text {st }}$ International Conference on Business and Engineering Management (IConBEM)

February $1^{\text {st }} 2020$, Institut Teknologi Sepuluh Nopember, Surabaya, Indonesia

\section{IV.CONCLUSION AND SUGGESTION}

\section{A. Conclusion}

1) Waste that gives the most significant influences in the production process in PCB section are transportation (W8 and W7), waiting (W6 and W5) and inventory (W3).

2) The root causes of waste problems that arise in the production process in PCB section include S3 (production duration of each process is different), S4 (The work station is not ergonomic), S5 (The company do not have a preventive maintenance schedule), S6 (There is no standard in handling defect product), S7 (Room layout that does not adjust the direction of the material), S8 (Capacity of hand truck for WIP transportation is small), and S9 (OQC process is not standard).

3) Recommendations for the improvement of speaker production in the proposed PCB section include WEA6 (conduct training to improve product repair skills), WEA2 (make preventive maintenance schedule), and WEA4 (relayout PCB MI room in the direction of material).

\section{B. Suggestion}

1) Calculate the results of improvements to the process cycle time after improvement.
2) The research phase is carried out until improvement implementation.

\section{REFERENCE}

[1] S. Nakajima, TPM Development Program: Implementing Total Productive Maintenance, 1st Editio. Portland Or.: Productivity Press, 1989.

[2] J. P. Womack and D. T. Jones, "Lean Thinking: Banish Waste and Create Wealth in Your Corporation," J. Oper. Res. Soc., vol. 62, no. 1, pp. 1-2, 1997, doi: 10.1057/jors.2010.172.

[3] J. F. Cox, J. H. Blackstone, and APICS--The Educational Society for Resource Management., APICS Dictionary, 9th ed. Athens: APICS, 1998.

[4] P. D. Karningsih, A. T. Pangesti, and M. Suef, "Lean Assessment Matrix: A Proposed Supporting Tool for Lean Manufacturing Implementation," IOP Conf. Ser. Mater. Sci. Eng., vol. 598, no. 1, 2019, doi: 10.1088/1757-899X/598/1/012082.

[5] M. A. Nash and S. R. Poling, Mapping The Total Value Stream : A Comprehensive Guide for Production and Transactional Processes. New York: CRC Press, 2008.

[6] R. A. Saputra and M. L. Singgih, "Perbaikan Proses Produksi Blender Menggunakan Pendekatan Lean Manufacturing Di Pt. Pmt," Pros. Semin. Nas. Manaj. Teknol. XV, pp. 1-9, 2012.

[7] R. J. and K. C. Latino, Root cause analysis : improving performance for bottom-line results, 2nd Editio. Boca Raton, Florida: CRC Press, 2002.

[8] I. A. Rawabdeh, "A Model for The Assessment of Waste in Job Shop Environments," Int. J. Oper. Prod. Manag., vol. 25, no. 8, pp. 800822, 2005, doi: 10.1108/01443570510608619. 